\title{
A study of the Web visibility of the SDGs and the 2030 Agenda on university websites
}

\author{
Mari Vallez \\ Department of Librarianship, Information Science and Audiovisual \\ Communication, University of Barcelona, Barcelona, Spain, and \\ Carlos Lopezosa and Rafael Pedraza-Jiménez \\ Department of Communication, Universitat Pompeu Fabra, Barcelona, Spain
}

Web visibility of the SDGs

\begin{abstract}
Purpose - Universities play an important role in the promotion and implementation of the 2030 Agenda for Sustainable Development. This study aims to examine the visibility of information about the Sustainable Development Goals (SDGs) on the websites of Spanish and major international universities, by means of a quantitative and qualitative analysis with an online visibility management platform that makes use of big data technology.

Design/methodology/approach - The Web visibility of the universities studied in relation to the terms "SDG", "Sustainable Development Goals" and "2030 Agenda" was determined using the SEMrush tool. Information was obtained on the number of web pages accessed and the queries formulated (query expansion). The content indexed by Google for these universities was compiled, and finally, the search engine optimization (SEO) factors applicable to the websites with the highest Web visibility were identified.

Findings - The universities analysed are content creators but do not have very high Web visibility in Web searches for information on the SDGs. Of the 98 universities analysed, only four feature prominently in search results.

Originality/value - Although research exists on the application of SEO to different areas, there have not, to date, been any studies examining the Web visibility of universities in relation to Web searches for information on the 2030 Agenda. The main contributions of this study are the global perspective it provides on the Web visibility of content produced by universities about the SDGs and the recommendations it offers for improving that visibility.
\end{abstract}

Keywords SDGs, 2030 Agenda, Spanish universities, SEO, Web visibility, Higher education institutions, Sustainable development goals (SDGs), Search engine optimisation (SEO)

Paper type Research paper

(C) Mari Vallez, Carlos Lopezosa and Rafael Pedraza-Jiménez. Published by Emerald Publishing Limited. This article is published under the Creative Commons Attribution (CC BY 4.0) licence. Anyone may reproduce, distribute, translate and create derivative works of this article (for both commercial and non-commercial purposes), subject to full attribution to the original publication and authors. The full terms of this licence may be seen at http://creativecommons.org/licences/by/4.0/ legalcode

This work is partially funded by the REDICE20-2800 project awarded by the Institute for Professional Development of the University of Barcelona. It is also part of the project "Interactive storytelling and digital visibility in interactive documentary and structured journalism”. RTI2018095714-B-C21 (MICINN/FEDER Spain).

SEMrush has been used in this study thanks to an agreement signed with the company to use the tool for research purposes.

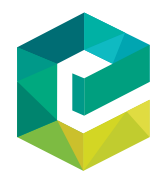

International Journal of Sustainability in Higher Education Vol. 23 No. 8,2022 pp. 41-59 $1467-6370$ DOI 10.1108/IJSHE-09-2021-0361 
IJSHE 23,8

\section{Introduction}

In September 2015, the United Nations General Assembly approved the 2030 Agenda for Sustainable Development, an international agreement involving a commitment to 17 Sustainable Development Goals (SDGs) aimed at fighting poverty, caring for the planet and reducing inequalities.

Given that two key elements of the 2030 Agenda are promoting universal access to information and ensuring quality education, it is important to understand how the SDGs are being communicated on the Web. With this in mind, this paper presents an analysis of online dissemination of the 2030 Agenda by certain stakeholders - specifically, universities - and the impact it has had on the Web visibility of the SDGs.

The role of universities in the pursuit of these goals is of considerable importance. Universities are institutions of knowledge engaged in the disciplinary areas necessary to ensure the implementation of the SDGs. Moreover, as organisations with considerable power and influence over civil society, universities need to be committed to participating actively in the implementation of the 2030 Agenda and should integrate its basic principles into their policies and strategies. In this context, the role that universities are playing in this endeavour is worthy of study.

At the same time, the internet has been consolidated as one of the predominant platforms for accessing information. This has meant that search engines like Google and Bing have turned into the primary source of information for many internet users. Furthermore, those users generally only take note of the hits that appear on the first search engine results page (SERP), while ignoring those appearing on subsequent pages (Kulshrestha et al., 2018). Search engines are essential to the online ecosystem; in fact, a report by BrightEdge Research (2019) estimates that an average of $53.3 \%$ of website traffic comes from organic searches. In other words, more than half of the traffic that a website receives arrives via search engines.

The analysis of factors influencing search results is known as search engine optimisation (SEO). The application of an SEO strategy is key to the success of a website, as it optimises the positioning of its pages. In other words, it helps ensure that they appear in the top positions of the SERP in response to a user query, thereby increasing the website's traffic and therefore, its Web visibility (Duong, 2019).

To address this research gap, this paper presents an analysis of the Web visibility (understood in terms of appearance in organic search results) of content created by universities about SDGs. The analysis includes both public and private universities in Spain, as well as a selection of international universities ranked at the top of the Times Higher Education World University Rankings (THE). The data obtained offers a picture of the situation in Spain, while at the same time facilitating the identification of any differences at the international level.

The specific objectives that have been defined for this study are:

- to determine the Web visibility of the 2030 Agenda and the SDGs on the websites of Spanish universities and of top international universities;

- to verify whether there are any differences between Spanish universities and the top international universities in terms of Web visibility; and

- to identify SEO best practices that can be applied to university websites to increase Web visibility.

The next section offers a review of the literature exploring how universities are working with the SDGs and on the principles of web visibility and SEO. This is 
followed by a description of the methodology and tools used to collect information facilitating the evaluation of the Web visibility of the universities studied. The results are then presented and discussed, and finally, some conclusions are offered, together with a consideration of the study's limitations and of possible lines of future research.

\section{Literature review}

Since the declaration of the 2030 Agenda in 2015, research on the SDGs at universities has become a focus of interest. The most prominent topics in this field of study have included the implementation of the SDGs, challenges and benefits associated with their application, trends in sustainable development education and promotion strategies.

Some studies have sought to identify the obstacles to the effective establishment of sustainable development at universities, finding that higher education institutions still need to do more to integrate sustainability into their curricula and research groups (Leal Filho et al., 2017; Chaleta et al., 2021) and even into their strategic plans (Bieler and McKenzie, 2017; Stoian et al., 2021).

Measures recommended to address this situation include the creation of formal structures that could not only help to overcome these limitations but also ensure that students develop a stronger commitment to the principles associated with sustainability (Leal Filho et al., 2019). Leicht et al. (2018) offer a series of suggestions to promote a comprehensive and transformative education experience that could enable students to make informed, responsible decisions to achieve genuine sustainable change. Annan-Diab and Molinari (2017) propose specific actions such as the application of corporate social responsibility plans.

Studies of the visibility of the Agenda 2030 on university websites can offer a complementary perspective to such research. It is worth highlighting, however, that the scientific literature related to Web visibility is not extensive. The most notable studies to date have focused on the analysis of Web visibility in relation to specific areas such as politics (Mustafaraj et al., 2020), tourism (Rovira et al., 2010) or health (Cano-Orón, 2019), or the application of SEO strategies in different sectors predominantly involving business websites (Schultheiß and Lewandowski, 2021) or online media (Giomelakis and Veglis, 2015; Lopezosa et al., 2020). There have also been studies conducted with search engine positioning tools such as SEMrush (Vyas, 2019), Sistrix (Lopezosa et al., 2019; Vállez and Ventura, 2020) or Majestic (García-Carretero et al., 2016).

Among the subject areas that have received the most scholarly attention, research on the Web visibility of social issues is particularly prominent. There have been studies demonstrating that the use of search engines like Google, Yandex or Baidu plays a vital role in providing information during elections, which has significant implications for information consumption (Metaxas and Pruksachatkun, 2016; Trielli and Diakopoulos, 2020). It is also worth noting the findings that the top search results generally come from national media outlets (Unkel and Haim, 2019), which therefore play a crucial role in constructing the image of political candidates (Belt et al., 2012). The importance of the SDGs to society and the role that politics plays in their implementation makes an analysis of the Web visibility of the 2030 Agenda and the SDGs particularly valuable.

It is also important to stress that getting to the top of search query results is no simple task, as to make it happen Web designers need to apply techniques commonly 
IJSHE 23,8

known as SEO strategies. SEO covers a whole range of strategies applied both within and outside the website to push it higher up in the search results. This is important because the best positioned content has the highest Web visibility and therefore the most Web traffic.

Notable among the studies of SEO positioning techniques and factors is the research by Shahzad et al. (2020) and Mittal et al. (2018) focusing on the three most widely used SEO techniques ("white hat", "grey hat" and "black hat"), which reveal that applying ethical ("white hat") positioning techniques is the safest and most enduring strategy. Umenhofer (2019), who studies SEO from the perspective of increasing a website's traffic, points out that the use of HTML title tags and metatags together with a keyword identification strategy can have a bigger impact than other SEO techniques. Windia et al. (2018) find that the best SEO techniques are optimising the meta-description, using unique focus keywords and applying alt attributes, especially to images. Yudasubrata et al. (2019), who explore methods for identifying keywords, highlight geotargeting as a differentiating factor.

There are also numerous studies focusing on the Web visibility of cultural institutions. Krstic and Maslikovic (2019) identify the problems that commonly affect this kind of website, with special attention to organic searches. Badchikar and Bhat (2019) analyse the basic concepts associated with website optimisation for search engines and the application of rankings to web pages, placing particular emphasis on how to begin applying these techniques. Niranjika and Samarasighe (2019) point out that quality content and the presence of external links ("backlinks") are extremely important for website positioning. A study by Krrabaj et al. (2017) confirms that the most important factors for optimising a website for search engines are quality content, backlinks and website accessibility on different types of devices (computers, mobiles and tablets). Research by Ziakis et al. (2019) identifies the main factors contributing to website positioning to be the adoption of an secure sockets layer certificate for the website, including the keyword in the uniform resource locator (URL), the number of links external to the website, the length of the text and the age of the domain.

The visibility of universities is a subject with a long history in the academic literature (Björneborn and Ingwersen, 2004; Thelwall et al., 2005). Launched in 2004, the Webometrics Ranking of World Universities is an academic ranking system that rates the online presence and impact of academic institutions (Aguillo et al., 2008). There are various international rankings of a similar nature, and their success is because of the evolution of the globalisation process affecting higher education (Aguillo et al., 2010). Apart from such "webometric" research, in recent years, there have been various studies of SEO specific to the academic sphere. These studies have dealt with questions such as the application of SEO techniques to the dissemination of academic production (Codina, 2017; Shahzad et al., 2017), the optimisation of academic articles in Google Scholar (Beel et al., 2009), the visibility of universities on academic social media platforms (French and Fagan, 2019; González-Díaz et al., 2015) and the use of SEO in repositories or academic journals. However, there are very few studies dealing specifically with SEO and the visibility of universities on search engines. One such study is by Giannakoulopoulos et al. (2019), who analyse the relationship between a university's academic excellence and its Web visibility. Most existing studies focus on specific areas, either geographically (Yalcin and Kilic, 2016) or thematically (Özkan et al., 2019).

Another line of research in this area that has been given considerable attention in recent years is the search engine manipulation effect. This is a term coined by Epstein and Robertson (2015), who define it as the manipulative effect that search engines can exert on users, which is masked in such a way that users are unable to recognise that it is happening. 
This bias has been studied not only in search engines but also in social media platforms and user profiles (Kulshrestha et al., 2018; Azcorra et al., 2018; Epstein et al., 2017) and even in relation to other search engine functions such as the search suggestion effect, whereby autocomplete suggestions influence the queries formulated (Bonart et al., 2019). As this phenomenon has an impact on both users and content creators, there has been a proliferation of studies focusing on the manipulation of search algorithms (Petre et al., 2019; Ziewitz, 2019) and on the neutrality and objectivity of search engines and their search results (Zheluk et al., 2012; Bilic, 2016).

\section{Methodology}

This study analyses the Web visibility of content related to the SDGs on university websites using a quantitative design involving the collection of Web visibility data for the 98 universities analysed. Based on the identification of the best positioned content, a qualitative analysis is conducted to identify best practices that could be useful for universities to adopt.

The list of public and private Spanish universities analysed is based on the information available on the EDUCAbase database maintained by the Spanish Ministry of Education and Professional Training/Ministry of Universities, which contains data on Spain's university network. A group of international universities have also been analysed to provide an international perspective and to provide other points of reference against which the results can be validated. The international universities in the sample were selected using the THE World University Rankings 2021, divided into two groups:

(1) the six top universities in the general ranking; and

(2) the six top universities in the Impact Rankings 2021 (THE-SDGs), which assess universities against the SDGs, defining various indicators that facilitate a comparison based on four areas: research, teaching, stewardship and outreach.

This second group actually includes seven universities because two were tied for the same position. Table 1 presents a summary of the 98 universities analysed.

The data on the universities' Web visibility have been obtained using the SEMrush platform. SEMrush is an internationally recognised SEO tool (ranked as one of the best of its kind by experts in the field) that uses big data technology and offers one of the largest databases on the market, containing 20 billion keywords and crawling 17 billion URLs each day.

This platform has been used to monitor the websites of the 98 universities analysed to determine their positioning for three keywords: "sustainable development goals", "2030 Agenda" and "SDGs". To obtain information on Spanish universities, the Spanish translations of these terms were used, submitting queries in the search engine Google.es via the SEMrush tool and taking into account the first 100 hits retrieved by the search engine for the geographical domain of Spain. For the international universities, the terms in English were used in the Google search engine for the country of each university, using the same platform. For example, Figure 1 shows the information collected with SEMrush from Google.co.uk to analyse the visibility of the University of Cambridge (cam.ac.uk) for the

\begin{tabular}{llrrr}
\hline & \multicolumn{2}{c}{ Spanish } & & \multicolumn{2}{c}{ International } \\
University & Public & Private & THE Ranking & THE-SDGs Ranking \\
\hline
\end{tabular}

\section{5}


IJSHE

23,8

46

three terms indicated above. The different queries formulated by users were identified, applying query expansion techniques (Efthimiadis, 1996). This process was repeated for the 98 universities studied to create an extensive corpus of data that can be consulted in Figshare (Vállez et al., 2021). The data were collected during the month of May 2021.

A control test was carried out with Sistrix, another SEO tool with similar features, to ensure that the results obtained with SEMrush did not offer a skewed picture of the websites. The results gathered in the control test (Appendix - Table A1) confirm the alignment of the information obtained on the two platforms.

In addition, information and data were compiled on the number of Google-indexed pages dealing with SDGs on the websites of the universities analysed. Google was chosen as the reference search engine because it is the one that currently has the biggest market share $(92.4 \%)$ [1]. Specifically, the data collection focused on identifying how many web pages on each university website dealing with the topic of SDGs are indexed by Google. To this end, we searched for web pages on each university domain that contained any of the three keywords in their title tag. For example, to obtain the pages on the University of Cambridge website with the term "SDGs" in its title, the advanced search command "allintitle:SDG site: cam.ac.uk" was entered in the search engine Google.co.uk. The option of collecting the information based on the URL with the command "allinurl:SDG site:cam.ac.uk" was also considered, but ultimately, it was decided to analyse the content of the HTML title attribute because its use was more common and because of the influence it has on the Web positioning of website pages. The data were collected on 30 June 2021 using the national version of the Google search engine for the country of each university analysed. Figure 2 shows the data collected for the ten universities with the most indexed content.

Figure 1.

Data collected on the University of Cambridge with SEMrush
Figure 2 .

Top ten universities with the most indexed content on Google, showing the number of pages indexed for each term and the total combined number

$\begin{array}{lll}\text { University } & \text { Domain } & \text { Keyword } \\ \text { University of Cambridge } & \text { cam.ac.uk } & \text { sdg icons } \\ \text { University of Cambridge } & \text { cam.ac.uk } & \text { un sdgs list } \\ \text { University of Cambridge } & \text { cam.ac.uk } & \text { sdgs } 17 \text { gosls } 169 \text { targets } \\ \text { University of Cambridge } & \text { cam.ac.uk } & \text { objectives of sustainable development goals } \\ \text { University of Cambridge } & \text { cam.ac.uk } & \text { un sustainable development goals list } \\ \text { University of Cambridge } & \text { cam.acuk } & \text { sustainable development goals icons } \\ \text { University of Cambridge } & \text { cam.ac.uk } & 2017 \text { sustainable development goals } \\ \text { University of Cambridge } & \text { cam.ac.uk } & \text { list of sdgs and targets } \\ \text { University of Cambridge } & \text { cam.ac.uk } & \text { unsdg } \\ \text { University of Cambridge } & \text { cam.ac.uk } & \text { un sdg } 17 \text { goals }\end{array}$

\begin{tabular}{|c|c|c|c|c|c|c|}
\hline University & Acronym & Domain & $\begin{array}{l}\text { Terml: } \\
2030 \\
\text { Agenda }\end{array}$ & $\begin{array}{l}\text { Term2: } \\
\text { Sustainable } \\
\text { Derolpmente } \\
\text { Goals }\end{array}$ & $\begin{array}{l}\text { Term3: } \\
\text { SDG }\end{array}$ & Total "Allintitle" - \\
\hline Universidad de La Rioja & UNIRIOJA & unirioja.es & 416 & 361 & 367 & 1,144 \\
\hline Universidad de Valencia & UV & uv.es & 158 & 107 & 466 & $731 \square$ \\
\hline Universidad Politécnica de Mauria & UPM & upgm.es & 107 & 299 & 219 & $625 \square$ \\
\hline Universidad Nacional de Educación a Dista... & UNED & unedes & 91 & 119 & 387 & $397 \square$ \\
\hline Univervidad de Murcia & UM & um.es & 67 & 74 & 393 & $534 \square$ \\
\hline Universidad de Zaragoza & $\mathrm{uz}$ & unizar.es & 126 & 105 & 187 & $418 \square$ \\
\hline Universidad de Barcelona & UB & ub.edu & 81 & 22 & 268 & $371 \square$ \\
\hline Harvard University & HARVARD & harvardedu & 10 & 171 & 184 & $365 \square$ \\
\hline Universidad Politécnica de Valencia & UPV & upves & 78 & 28 & 205 & $311 \square$ \\
\hline Massachusetts Institute of Technology & MIT & mitedu & 3 & 41 & 263 & $307 \square$ \\
\hline
\end{tabular}

\begin{tabular}{|c|c|}
\hline URL & Position \\
\hline https:/unw:cisl cam ac uk about youn ... & 17 \\
\hline https:/ www: conservation cam ac.uk Ke ... & 31 \\
\hline 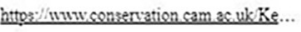 & 36 \\
\hline https:/ /1w1w: conservation cam ac.uk $\mathrm{Ke}$... & 59 \\
\hline hrtog:/inww:conservation cam ac.uk Ke... & 72 \\
\hline htros://1n11wicisl cam ac uk about youn... & 72 \\
\hline https:/4ww. cisl. cam ac uk resources'su... & $\$ 3$ \\
\hline htrog:/ wnw.consertation cam ac.uk Ke... & $\$ 4$ \\
\hline 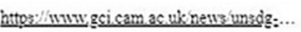 & $\$ 5$ \\
\hline https:/ w1ww: conservation cam ac.uk Ke.. & $\$ 6$ \\
\hline
\end{tabular}


Finally, a qualitative analysis was carried out to examine the SEO techniques applied to the web pages with higher Web visibility. To this end, 20 indicators were applied, based on the studies cited in the "Literature review" section. The indicators refer to the main strategies for the effective search engine optimisation of a website. An analysis of the most visible content with the 20 indicators served to identify best practices to enhance the Web visibility of universities in relation to the SDGs.

\section{Results}

The results obtained on the Web visibility of the universities studied in relation to the three aforementioned SDG-related keywords are outlined below.

The data collected using the SEMrush tool, which have served as the basis for subsequent analysis, are presented in Figure 3. The global data processed are:

- the number of times that the university website pages have appeared as search engine results in one of the top 100 positions on the SERPs;

- the number of unique university website pages that have been shown as a result; and

- the number of queries entered (keywords) with results that include a web page of one of the universities analysed.

The funnel-shaped image in Figure 3 presents the data from the most general to the most specific: the total number of web pages retrieved, different web pages and queries entered by users in the search engine to access content on SDGs.

Figure 4 shows the breakdown of the data collected into the three groups of universities analysed: Spanish public universities, Spanish private universities and prestigious
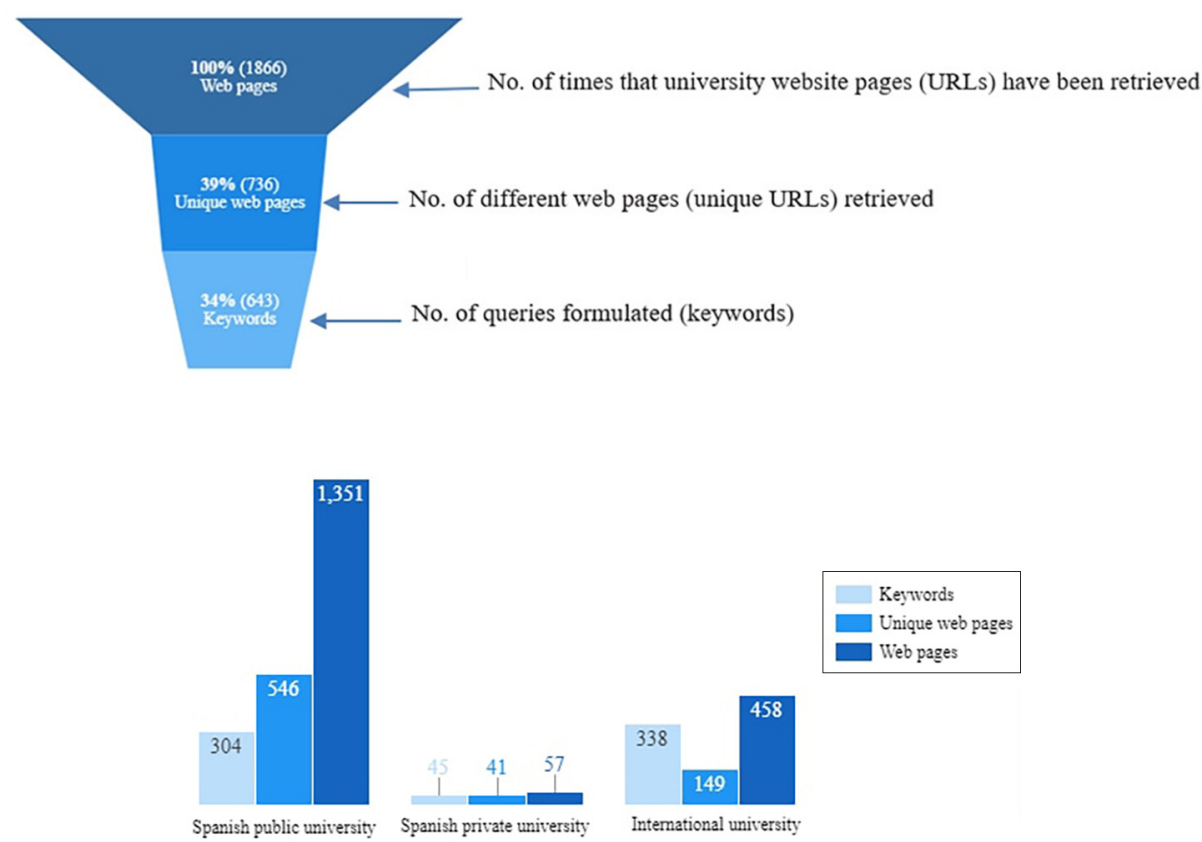

458

Intemational university
Web visibility of the SDGs 
IJSHE

23,8

\section{8}

Figure 5.

Top ten universities with highest Web visibility

\section{Figure 6.}

Universities with the highest percentage of web pages positioned on the first SERP international universities. The international universities are analysed as a single block in this figure to provide a general picture of the international context, although the disaggregated data are analysed further below, as indicated in the "Methodology" section.

The results reveal that Spanish private universities have almost no visibility in relation to the three terms associated with SDGs. In the case of the international universities, it is worth noting that the number of keywords used to access the content is higher than the number of different web pages; this is normal in a SEO analysis because the same content can be accessed using various keywords. However, this is not the case for Spanish universities, as there are fewer keywords than unique web pages, which means that there are fewer ways to access the content.

The next step was to analyse the Web visibility of the SDG concept, with the three variants indicated above, for each of the university websites analysed. Figure 5 shows the ten universities with the highest Web visibility for the terms selected, indicating their domain name, the number of web pages positioned in the search results and the number of these that are unique web pages.

Another question of interest is the percentage of web pages that universities have in the top ten positions (and therefore on the first page) of the search engine results. Figure 6 shows the universities with the most web pages in the top ten, indicated as a percentage of

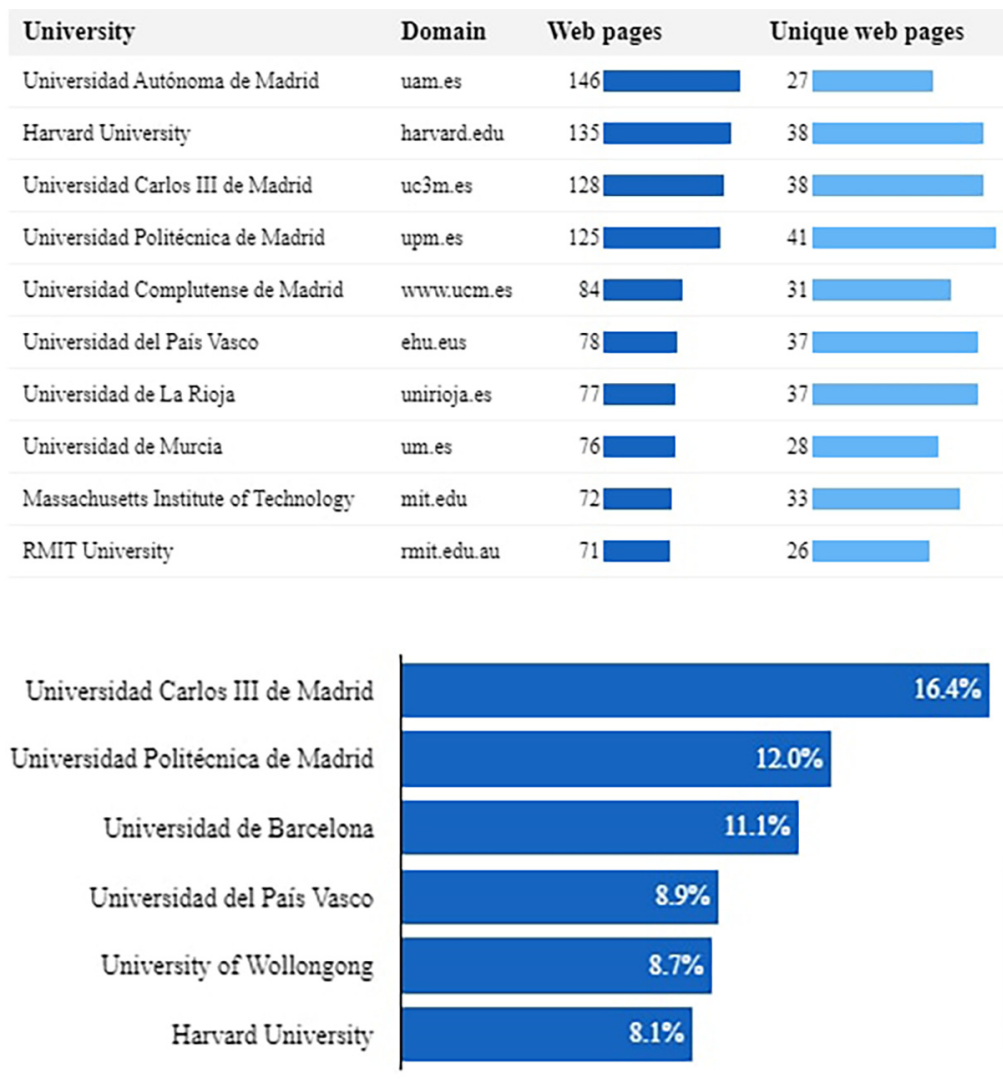


the total number of web pages that each university placed in the results. This point is important because it suggests that Universidad Carlos III in Madrid is applying better SEO techniques so that the search engines are positioning more of its content in the top search results. It can also, thus, be concluded that this university is communicating information on the SDGs more effectively.

Looking more closely at the case of universities in Spain, Figure 7 compares the levels of Web visibility of the two types of Spanish universities. As the figure shows, $63 \%$ of the 35 private universities have no visibility at all, i.e. their web pages never appear in any organic search engine results for queries related to the SDGs. Conversely, $90 \%$ of public universities have at least one web page on the SDGs positioned in search engine results. Moreover, only $9 \%$ of private universities have more than ten visible web pages, while for public universities, that figure is $56 \%$.

To provide a more detailed picture of the Web visibility of Spanish public universities, the graph in Figure 8 shows that three universities dominate Web visibility, with more than 100 web pages accessed via the search engine with the keywords associated with the SDGs. On the next level, there are eight universities with 50-100 web pages appearing in the search engine results. This means that these 11 universities are responsible for $70 \%$ of all web pages accessed on sustainable development. On the other end of the scale, just $4 \%$ of the universities had no web pages at all related to the terms studied.

The next step was to analyse the Web visibility of the international universities to identify any significant differences from the data obtained on Spanish universities. To this
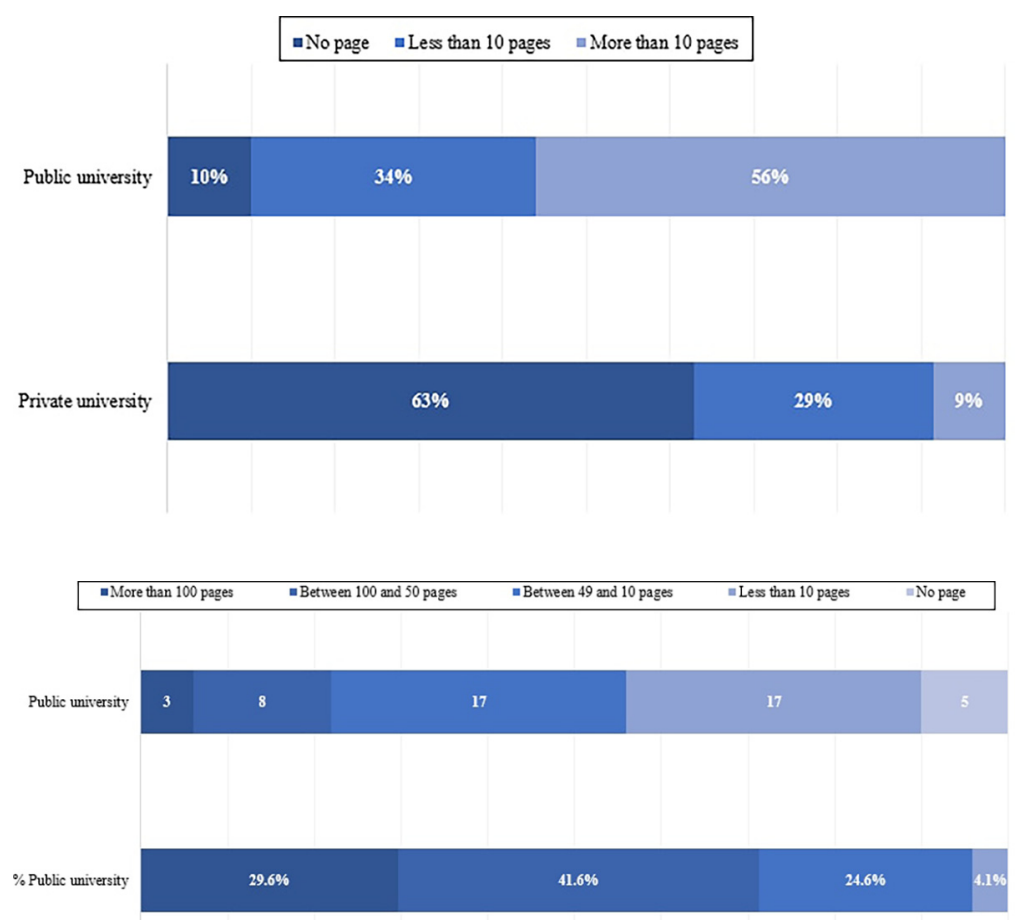

Web visibility of the SDGs

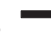


IJSHE 23,8

Figure 9.

(a) Top six

universities on THE

Ranking (left); (b) top

six universities on

THE-SDGs Ranking (right)

end, the universities selected were analysed according to the two criteria outlined in the "Methodology" section. Figure 9 lists the international universities and indicates the number of web pages positioned in the search results and how many are unique web pages for the keywords associated with SDGs. The universities analysed are split into the two groups described in the "Methodology" section:

(1) the top six universities on the Ranking; and

(2) the top six universities on the THE-SDGs Ranking

As reflected in Figures 5 and 9, there are no significant differences between Spanish and international universities, as the top universities in the two cases have similar numbers of web pages, although the international sample is much smaller. Of the international universities analysed, those in the USA (Harvard and MIT) are better positioned than their British counterparts (Cambridge and Oxford), which have very few web pages accessed. However, it is worth highlighting that the highest ranked international universities in relation to the SDGs (Figure 9b), many of which are Australian, have much lower Web visibility. There is not really any reason for there to be a connection between the two variables, as the THE-SDGs Ranking does not take this aspect into account.

The next question analysed in this study aims to contextualise the data presented so far by examining the amount of information about SDGs on university web pages that is indexed by Google (considering the three terms referred to in the "Methodology" section). This will help to identify whether there is any correlation between the number of web pages accessed on each university website and the number of pages indexed by Google. To this end, the 20 best-positioned Spanish universities and all 13 international universities were analysed. Figure 10 shows two separate scatter plots for the Spanish universities (Figure 10(a)) and the international universities (Figure 10(b)). Each university is represented as a point located on the $\mathrm{X}$ axis (number of visible web pages) and $\mathrm{Y}$ axis (number of pages indexed by Google).

\begin{tabular}{|c|c|c|c|c|c|c|c|}
\hline University & Domain & Web pages & $\begin{array}{l}\text { Unique } \\
\text { web pages }\end{array}$ & University & Domain & Web pages & $\begin{array}{l}\text { Unique } \\
\text { web pages }\end{array}$ \\
\hline Harvard University & harvard.edu & 135 & $38 \square$ & RMIT University & miteduau & 71 & 26 \\
\hline Massachusetts Institute of Tech... & mitedu & $72 \square$ & 33 & University of Manchester & manchester.ac.uk & 57 & $7 \square$ \\
\hline University of Cambridge & cam.ac.uk & 141 & $5 \|$ & University of Wollongong & uow.edu.au & 54 & $12 \square$ \\
\hline Stanford University & stanford.edu & 121 & $11 \square$ & Queen's University & queensu.ca & $19 \square$ & 21 \\
\hline University of Oxford & ox ac.uk & 91 & 9 & University of Sydney & sydney.edu.au & $15 \square$ & $6 \square$ \\
\hline \multirow[t]{2}{*}{ Califomia Institute of Technology } & caltech edu & 이 & 이 & La Trobe University & latrobe.edu.au & 이 & 이 \\
\hline & & & & Aalborg University & en aau dk & 이 & 이 \\
\hline
\end{tabular}

Figure 10.

Scatter plot: (a) Spanish universities (left); (b) international universities (right)
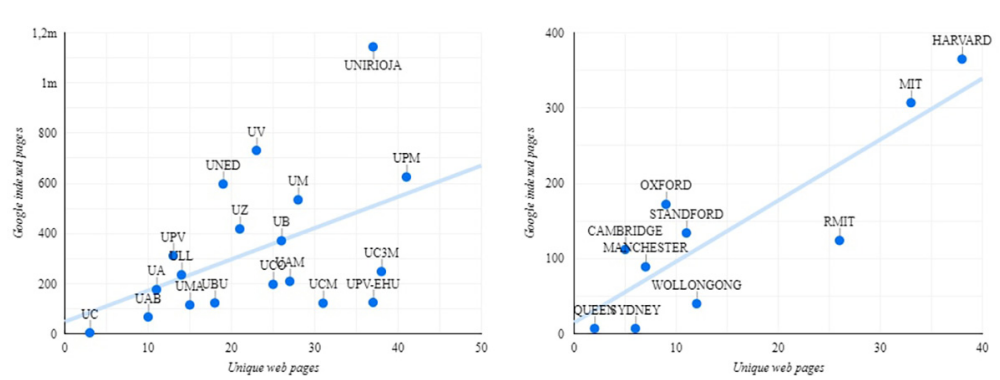
The correlation coefficient obtained for the Spanish universities is 0.47 , reflecting the existence of a moderate positive correlation between the two values, as shown by the trend line in Figure 10(a). However, in the case of the international universities the correlation coefficient is 0.86 , constituting a high positive correlation between the two variables, as evidenced by the trend line in Figure 10(b).

A comparison of the two graphs in Figure 10 reveals that the Spanish universities analysed have more content indexed in Google than the international universities. On the other hand, the number of unique web pages is similar for the two groups. Looking at specific cases, Figure 10(a) shows that Universidad de La Rioja is the university with the largest number of indexed web pages. This could be explained by the fact that the Dialnet bibliographic database, which compiles scientific literature in Spanish, is hosted on this university's domain.

Drawing on this specific example, we analysed which university subdomains give SDGs the highest levels of visibility, as this may help to identify the characteristics of such content. Table 2 shows the ten university subdomains with the highest Web visibility.

The results show that Universidad Autónoma de Madrid (UAM) is the university with the highest Web visibility, with a specific subdomain dedicated to SDGs ("ODS" in Spanish) that generates more than $90 \%$ of all results. The findings also reveal a significant number of subdomains associated with scientific production (repositories or journals) on the websites of Harvard University, MIT and Universidad Complutense de Madrid (UCM), among others. This suggests that such subdomains constitute an effective way for universities to boost their Web visibility. Finally, it is important to note that only a small number of subdomains were identified (16), yet they contain $31 \%$ of all visible web pages. Most universities do not have specific subdomains to boost their Web visibility in relation to the SDGs, and therefore, their visibility is derived directly from their general websites.

Table 3 presents an analysis of the specific SEO techniques identified in the subdomain with the highest visibility: UAM's SDG subdomain (ods.uam.es).

\begin{tabular}{|c|c|c|c|c|}
\hline University & $\begin{array}{l}\text { Subdomain description (from HTML } \\
\text { title tag) }\end{array}$ & Subdomain & Freq. & \\
\hline UAM & $\begin{array}{l}\text { ODS - Objetivos de Desarrollo } \\
\text { Sostenible }\end{array}$ & ods.uam.es & 132 & \\
\hline Harvard & $\begin{array}{l}\text { Repository - Global Health education } \\
\text { and learning incubator } \\
\text { The Harvard Law School Forum on } \\
\text { Corporate Governance }\end{array}$ & $\begin{array}{l}\text { repository.gheli. } \\
\text { harvard.edu } \\
\text { corpgov.law.harvard. } \\
\text { edu }\end{array}$ & 89 & \\
\hline UNIRIOJA & $\begin{array}{l}\text { Dialnet } \\
\text { Fundación Universidad de La Rioja }\end{array}$ & $\begin{array}{l}\text { dialnet.unirioja.es } \\
\text { fundacion.unirioja.es }\end{array}$ & 70 & \\
\hline MIT & $\begin{array}{l}\text { MIT Media Lab } \\
\text { MIT Sloan Management Review }\end{array}$ & $\begin{array}{l}\text { www.media.mit.edu } \\
\text { sloanreview.mit.edu }\end{array}$ & 46 & \\
\hline $\mathrm{UCM}$ & $\begin{array}{l}\text { Archivo Institucional E-Prints } \\
\text { Complutense } \\
\text { Revistas Científicas Complutenses }\end{array}$ & $\begin{array}{l}\text { eprints.ucm.es } \\
\text { revistas.ucm.es }\end{array}$ & 42 & \\
\hline UPM & $\begin{array}{l}\text { Centro de Innovación en Tecnología } \\
\text { para el Desarrollo itdUPM }\end{array}$ & www.itd.upm.es & 68 & \\
\hline UB & Fundació solidaritat UB & www.solidaritat.ub.edu & 60 & Table 2. \\
\hline URLL & RIULL - Repositorio institucional & riull.ull.es & 17 & Most visible \\
\hline UVA & Sostenibilidad Uva & ods.uva.es & 14 & university \\
\hline UA & Servicio de Relaciones Internacionales & sri.ua.es & 13 & subdomains \\
\hline
\end{tabular}




\section{IJSHE \\ 23,8}

52

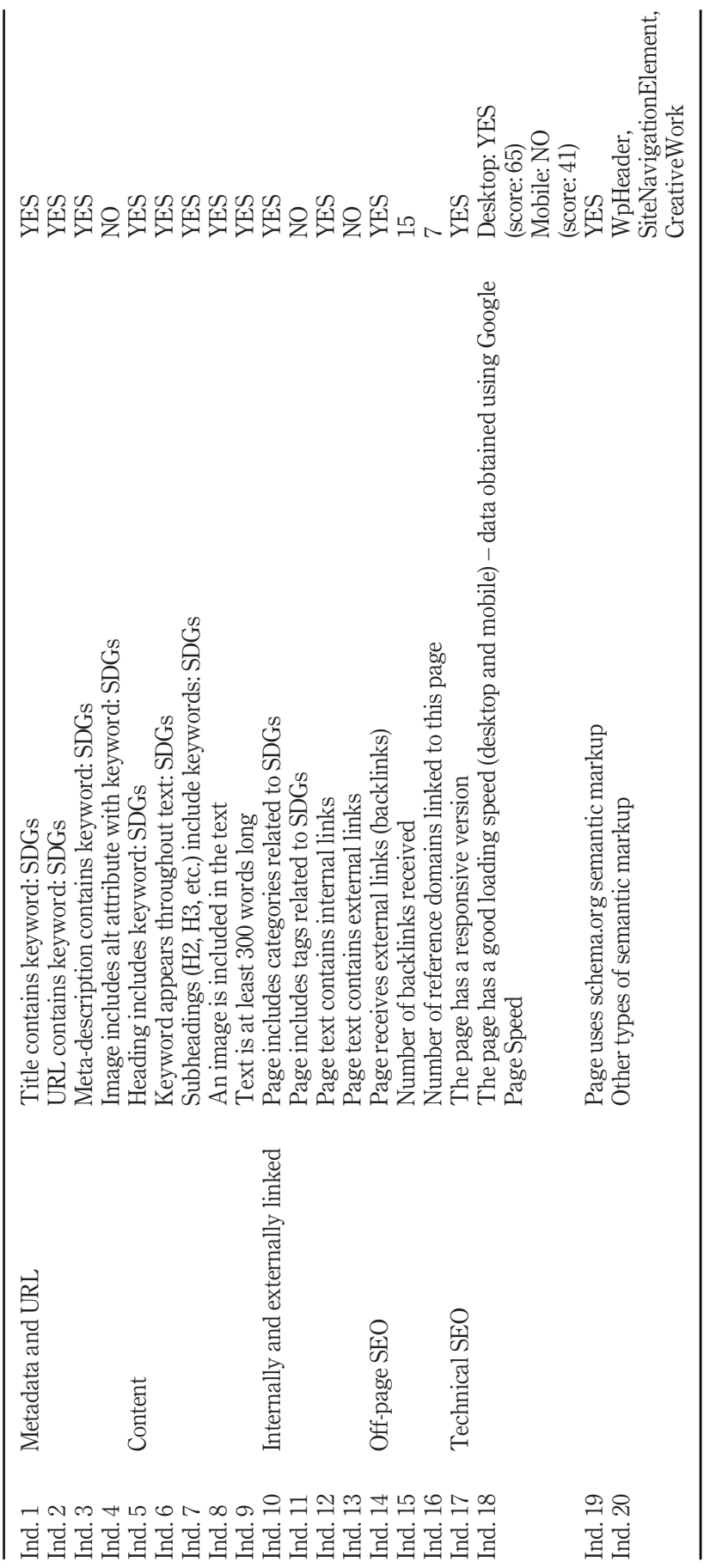

Table 3.

SEO analysis of the subdomain "La agenda 2030 y los ODS en la UAM" (ods.uam.es) 
The website analysed applies 17 of the 20 indicators identified, thereby confirming that the application of SEO techniques has helped "ods.uam.es" to improve its positioning for queries related to SDGs and also to achieve good ranking positions.

Finally, we sought to identify which keywords (i.e. what type of queries formulated in the search engine) universities are positioned for. Figure 11 shows a list of the ten main keywords and their frequency for positioning Spanish universities (Figure 11(a)) and international universities (Figure 11(b)).

The two lists reveal some striking differences between Spanish and international universities, in keeping with the results observed previously in Figure 4 (lower volume of keywords for Spanish universities). The keywords of Spanish universities have a higher frequency and are made up of a combination of just a few terms. On the other hand, for international universities the frequency is lower, resulting in a "long tail" of much more specific keywords combining several terms. Moreover, specific questions are formulated with the use of interrogative words.

\section{Discussion}

As institutions of knowledge and content generation, universities play an important role in the 2030 Agenda and the implementation of the SDGs (Leal Filho, 2020). The positioning of the content they create related to this topic is, therefore, worthy of study. The analysis of their Web visibility in this study constitutes an original contribution to research in this field, as although communication - specifically, online communication - is identified by the European Sustainable Development Network as key to the Agenda's implementation (Mulholland et al., 2017; Mulholland, 2019), no previous studies have referred explicitly to web visibility.

In general terms, the results of this research reveal that although universities are content creators, they are not prominent in search engine results for queries seeking general information on the 2030 Agenda and SDGs. This situation is not unique to Spanish universities, as the pattern is very similar for the international universities at the top of the THE Ranking. Of the 98 universities analysed, only four stand out for their high number of hits: UAM, Harvard University, Universidad Carlos III de Madrid and Universidad Politécnica de Madrid. The rest of the universities analysed have fewer than 100 web pages positioned in the search results and $30.6 \%$ of the universities analysed have no web pages in the results at all. To ensure that the tool used in this study (SEMrush) had not produced

$\begin{array}{lcll}\text { Keyword } & \text { Freq. } & \text { Keyword } & \text { Freq. } \\ \text { ods en la universidad } & 34 & \text { un sdg } & 5 \\ \text { master ods } & 28 & \text { un sdg goals } & 5 \\ \text { actividades ods } & 13 & \text { what is un sustainable development goals } & 4 \\ \text { ods voluntariado } & 13 & \text { united nations sustainable development goals } & 4 \\ \text { ods } 10 & 12 & \text { sdgs } & 4 \\ \text { ods } 2013 & 12 & \text { sustainable development goals } & 4 \\ \text { declaracion de los objetivos de desarrollo sostenible } & 11 & \text { who sustainable development goals } & 4 \\ \text { objetivos de desarrollo sostenible ods } & 11 & \text { what is sustainable development goals } & 4 \\ \text { logo ods } & 10 & \text { un sustainable development goals } & 4 \\ \text { que es odm y ods } & 10 & \text { un sdgs } & 4\end{array}$

Web visibility of the SDGs

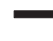


IJSHE 23,8

skewed results, the Sistrix platform was also applied. The results obtained with the two platforms were similar, as reflected in Table A1 in the Appendix.

The analysis of international universities (most of which are American, British or Australian) confirms that there are no substantial differences between international and Spanish universities. However, it is striking that the top universities in the Impact Rankings 2021 (THE-SDGs) did not obtain the best results, as only one of them was positioned among the top ten and even that university was only in tenth place. This finding confirms the suggestion that universities have limited Web visibility in this area, despite the fact that they have integrated the SDG philosophy into their institutional strategies.

The poor Web visibility of universities in relation to the SDGs confirmed in this study may be due to two factors:

(1) universities produce largely academic content focusing much more on research than on education or outreach; and

(2) the general public is interested in the issues addressed by the SDGs but is not familiar with the specific terminology used to designate them.

Finally, the various findings of this study point to some best practices that could help improve the Web visibility of universities in relation to the SDGs:

- Establish a specific subdomain to centralise content on SDGs (e.g. https://ods.uam.es/).

- Facilitate the indexing of content by search engines, given that a positive correlation has been demonstrated between the two variables. The Google Search Console tool could be used to facilitate this process.

- Apply SEO techniques to optimise the website for search engines.

- Establish a strategy for receiving links from the university itself and from other institutions.

- Analyse the keywords used to access content.

- Create content that would help give visibility to the actions taken by the university (e.g. SDGs - RMIT University).

\section{Conclusions}

This section offers a review of the objectives of the study, as well as identifying its limitations and possible future lines of research.

In relation to the first objective, this study has determined the Web visibility of Spanish universities and the group of international universities analysed in relation to the SDG concept and the 2030 Agenda. It is clear that the Web visibility of universities has room for improvement. The dissemination of information by universities has been significant, especially Spanish public universities; however, with a few exceptions this has not had an impact on the number of keywords in search queries or on boosting their positioning in SERPs.

Based on the information obtained, a ranking was established of the universities with the highest levels of Web visibility in relation to the 2030 Agenda and the SDGs. Three aspects of this ranking are worth noting:

(1) the high levels of web visibility of universities in Madrid compared to other parts of Spain;

(2) the limited or non-existent dissemination of information by private Spanish universities; and 
(3) the generally low level of visibility of the most prestigious international universities

This last point responds to the study's second objective, as it confirms that Spanish universities are not an exception, as international universities have equally poor Web visibility in relation to the SDGs.

The third objective involved the identification of the factors behind the Web positioning of the best-positioned website (ods.uam.es). A qualitative analysis was conducted, finding that it met 17 of the 20 indicators established. This confirms the application of a good SEO strategy that has facilitated the positioning of more web pages in search engine results for a bigger number of keywords (search engine queries). Of course, analysing a single URL has limitations, as it does not permit generalisations. However, the sole purpose of examining this website was to confirm whether, in this context, there is also a direct correlation between the use of SEO techniques and the Web visibility of universities.

Another limitation of the study is the fact that the data presented cannot be considered conclusive but merely indicative of certain tendencies, as it is essentially an exploratory study aimed at drawing a few general conclusions. Finally, it is important to bear in mind that this research analyses SDGs in general without considering each of them individually.

This study could serve as a foundation for future lines of research, as the snapshot offered here of the Web visibility of the 2030 Agenda and the SDGs on Spanish university websites could be expanded to include more international universities beyond those included in this study. This would make it possible to compile a global ranking on the dissemination of the SDGs that could have significant social and informational implications, while also complementing the THE-SDGs Ranking. Another aspect worth analysing is the visibility of each of the 17 SDGs, or of those that receive more attention in the academic sphere, to develop a clearer picture of the role that universities are playing in the implementation of the 2030 Agenda.

\section{Note}

1. Data from StatCounter GlobalStats https:/gs.statcounter.com/search-engine-market-share (accessed 3 July 2021).

\section{References}

Aguillo, I., Ortega, J.L. and Fernández, M. (2008), "Webometric ranking of world universities: introduction, methodology and future developments", Higher Education in Europe, Vol. 33 Nos 2/3, pp. 233-244.

Aguillo, I., Bar-Ilan, J., Levene, M. and Ortega, J. (2010), "Comparing university rankings", Scientometrics, Vol. 85 No. 1, pp. 243-256.

Annan-Diab, F. and Molinari, C. (2017), "Interdisciplinarity: practical approach to advancing education for sustainability and for the sustainable development goals", The International Journal of Management Education, Vol. 15 No. 2, pp. 73-83.

Azcorra, A., Chiroque, L.F., Cuevas, R., Fernández, A., Laniado, H., Lillo, R.E., Romo, J. and Sguera, C. (2018), "Unsupervised scalable statistical method for identifying influential users in online social networks”, Scientific Reports, Vol. 8 No. 1, pp. 1-7.

Badchikar, A. and Bhat, V. (2019), "Search engine optimization with a B testing", International Journal of Recent Technology and Engineering, Vol. 8, pp. 4484-4488.

Beel, J., Gipp, B. and Wilde, E. (2009), "Academic search engine optimization (ASEO) optimizing scholarly literature for Google scholar and co”, Journal of Scholarly Publishing, Vol. 41 No. 2, pp. 176-190. 
IJSHE 23,8

Belt, T., Just, M. and Crigler, A. (2012), "The 2008 media primary: handicapping the candidates in newspapers, on TV, cable and the internet", The International Journal of Press/Politics, Vol. 17 No. 3, pp. 341-369.

Bieler, A. and McKenzie, M. (2017), "Strategic planning for sustainability in Canadian higher education”, Sustainability, Vol. 9 No. 2, p. 161.

Bilic, P. (2016), "Search algorithms, hidden labour and information control”, Big Data and Society, Vol. 3 No. 1, pp. 1-9.

Björneborn, L. and Ingwersen, P. (2004), "Perspective of webometrics", Scientometrics, Vol. 50 No. 1, pp. 65-82.

Bonart, M., Samokhina, A., Heisenberg, G. and Schaer, P. (2019), "An investigation of biases in web search engine query suggestions”, Online Information Review, Vol. 44 No. 2, pp. 365-381.

BrightEdge Research (2019), "BrightEdge's report", available at: https://videos.brightedge.com/ research-report/BrightEdge_ChannelReport2019_FINAL.pdf (accessed 12 July 2021).

Cano-Orón, L. (2019), "Dr Google, what can you tell me about homeopathy? Comparative study of the top10 websites in the United States, United Kingdom, France, Mexico and Spain”, El Profesional de la Información, Vol. 28 No. 2, pp. 1-12.

Chaleta, E., Saraiva, M., Leal, F., Fialho, I. and Borralho, A. (2021), "Higher education and sustainable development goals (SDG) - potential contribution of the undergraduate courses of the school of social sciences of the university of évora", Sustainability, Vol. 13 No. 4, p. 1828.

Codina, L. (2017), "SEO academic: definition, components and tools guide", available at: www. lluiscodina.com/seo-academico-guia/ (accessed 12 July 2021).

Duong, V. (2019), SEO Management: Methods and Techniques to Achieve Success, John Wiley and Sons, London.

Efthimiadis, E.N. (1996), "Query expansion”, Annual Review of Information Science and Technology, Vol. 31, pp. 121-187.

Epstein, R. and Robertson, R. (2015), "The search engine manipulation effect (SEME) and its possible impact on the outcomes of elections", Proceedings of the National Academy of Sciences, Vol. 112 No. 33, pp.E4512-E4521.

Epstein, R., Robertson, R., Lazer, D. and Wilson, C. (2017), "Suppressing the search engine manipulation effect (SEME)", Proceedings ACM Human-Computer Interaction, Vol. 1 No. CSCW, pp. 1-22.

French, R.B. and Fagan, J.C. (2019), "The visibility of authority records, researcher identifiers, academic social networking profiles and related faculty publications in search engine results", Journal of Web Librarianship, Vol. 13 No. 2, pp. 156-197.

García-Carretero, L., Codina, L., Díaz-Noci, J. and Iglesias-García, M. (2016), "Herramientas e indicadores SEO: características y aplicación Para análisis de cibermedios”, El Profesional de la Información, Vol. 25 No. 3, pp. 497-504.

Giannakoulopoulos, A., Konstantinou, N., Koutsompolis, D., Pergantis, M. and Varlamis, I. (2019), "Academic excellence, website quality, SEO performance: is there a correlation?", Future Internet, Vol. 11 No. 11, pp. 1-25.

Giomelakis, D. and Veglis, A. (2015), "Investigating search engine optimization factors in media websites, the case of Greece", Digital Journalism, Vol. 4 No. 3, pp. 379-400.

González-Díaz, C., Iglesias-García, M. and Codina, L. (2015), "Presence of Spanish universities in scientific digital social networks: the case of communication studies", El Profesional de la Información, Vol. 24 No. 5, pp. 640-647.

Krrabaj, S., Baxhaku, F. and Sadrijaj, D. (2017), "Investigating search engine optimization techniques for effective ranking: a case study of an educational site", 6th Mediterranean Conference on Embedded Computing (MECO), pp. 1-4. 
Krstić, N. and Maslikovic, D. (2019), "Pain points of cultural institutions in search visibility: the case of Serbia”, Library Hi Tech, Vol. 37 No. 3, pp. 496-512.

Kulshrestha, J., Eslami, M., Messias, J., Bilal, M., Ghosh, S., Gummadi, K. and Karahalios, K. (2018), "Search bias quantification: investigating political bias in social media and web search", Information Retrieval Journal, Vol. 22 Nos 1/2, pp. 188-227.

Leal Filho, W. (2020), "Viewpoint: accelerating the implementation of the SDGs", International Journal of Sustainability in Higher Education, Vol. 21 No. 3, pp. 507-511.

Leal Filho, W., Wu, Y.C.J., Brandli, L.L., Avila, L.V., Azeiteiro, U.M., Caeiro, S. and Madruga, L. of the SDGs (2017), "Identifying and overcoming obstacles to the implementation of sustainable development at universities", Journal of Integrative Environmental Sciences, Vol. 14 No. 1, pp. 93-108.

Leal Filho, W., Shiel, C., Paço, A., Mifsud, M., Ávila, L.V., Brandli, L.L., Molthan-Hill, P., Pace, P., Azeiteiro, U.M., Vargas, V.R. and Caeiro, S. (2019), "Sustainable development goals and sustainability teaching at universities: falling behind or getting ahead of the pack?", Journal of Cleaner Production, Vol. 232, pp. 285-294.

Leicht, A., Heiss, J. and Byun, W.J. (2018), Issues and Trends in Education for Sustainable Development, Unesco Publishing, Paris.

Lopezosa, C., Codina, L. and Pérez-Montoro, M. (2019), "SEO and digital news media: visibility of cultural information in Spain's leading newspapers”, Tripodos, Vol. 44, pp. 41-61.

Lopezosa, C., Codina, L., López-García, G. and Corbella-Cordomi, J. (2020), "Mapa de visibilidad y posicionamiento en buscadores de los principales grupos mediáticos españoles", El Profesional de la Información, Vol. 29 No. 2, pp. 1-15.

Metaxas, P. and Pruksachatkun, Y. (2016), "Manipulation of search engine results during the 2016 US congressional elections", paper presented at International Conference on Internet and Web Applications and Services (ICIW), 22-26 May, Valencia, Spain, available at: https://repository. wellesley.edu/object/ir264

Mittal, M.K., Kirar, N. and Meena, J. (2018), "Implementation of search engine optimization: through white hat techniques", International Conference on Advances in Computing, Communication Control and Networking (ICACCCN), pp. 674-678.

Mulholland, E. (2019), "Communicating sustainable development and the SDGs in Europe: good practice examples from policy, academia, NGOs and media”, ESDN Quarterly Report, Vol. 51, pp. 1-22.

Mulholland, E., Bernardo, A. and Berger, G. (2017), "Communication and awareness raising in the implementation of the 2030 agenda and the SDGs: Activities and challenges", ESDN Quarterly Report, Vol. 44, pp. 1-49.

Mustafaraj, E., Lurie, E. and Devine, C. (2020), "The case for voter-centered audits of search engines during political elections", Proceedings of the 2020 Conference on Fairness, Accountability and Transparency (FAT), pp. 559-569.

Niranjika, U. and Samarasighe, D. (2019), "Exploring the effectiveness of search engine optimization tactics for dynamic websites in Sri Lanka", Moratuwa Engineering Research Conference (MERCon), pp. 267-272.

Özkan, B., Özceylan, E., Kabak, M. and Dağdeviren, M. (2019), "Evaluating the websites of academic departments through SEO criteria: a hesitant fuzzy linguistic MCDM approach”, Artificial Intelligence Review, Vol. 53 No. 2, pp. 875-905.

Petre, C., Duffy, B.E. and Hund, E. (2019), "Gaming the system: platform paternalism and the politics of algorithmic visibility”, Social Media + Society, Vol. 5 No. 4, pp. 1-12.

Rovira, C., Fernández-Cavia, J., Pedraza-Jiménez, R. and Huertas, A. (2010), "Posicionamiento en buscadores de las webs oficiales de capitales de provincia españolas", El Profesional de la Informacion, Vol. 19 No. 3, pp. 277-283. 
IJSHE 23,8

Schultheiß, S. and Lewandowski, D. (2021), "Outside the industry, nobody knows what we do SEO as seen by search engine optimizers and content providers", Journal of Documentation, Vol. 77 No. 2, pp. 542-557.

Shahzad, A., Witarsyah, D., Mohd, N., Mahdin, H. and Saputri, M. (2020), "The new trend for search engine optimization, tools and techniques", Indonesian Journal of Electrical Engineering and Computer Science, Vol. 18 No. 3, pp. 1568-1583.

Shahzad, A., Nawi, N.M., Hamid, N.A., Khan, S.N., Aamir, M., Ullah, A. and Abdullah, S. (2017), "The impact of search engine optimization on the visibility of research paper and citations", JOIV : International Journal on Informatics Visualization, Vol. 1 Nos 4/2, pp. 195-198.

Stoian, C.E., Simon, S. and Gherhes, V. (2021), "A comparative analysis of the use of the concept of sustainability in the Romanian top universities' strategic plans", Sustainability, Vol. 13 No. 19, p. 10642.

Thelwall, M., Vaughan, L. and Björneborn, L. (2005), "Webometrics”, Annual Review of Information Science and Technology, Vol. 39 No. 1, pp. 81-135.

Trielli, D. and Diakopoulos, N. (2020), "Partisan search behavior and Google results in the 2018 U.S. midterm elections", Information, Communication and Society, Vol. 24 No. 4, pp. 1-17, doi: 10.1080/1369118X.2020.1764605.

Umenhofer, L. (2019), "Gaining ground: search engine optimization and its implementation on an indie book press”, Publishing Research Quarterly, Vol. 35 No. 2, pp. 258-273.

Unkel, J. and Haim, M. (2019), "Googling politics: parties, sources and issue ownerships on Google in the 2017 German federal election campaign”, Social Science Computer Review, Vol. 39 No. 5, pp. 1-18, doi: $10.1177 / 0894439319881634$.

Vállez, M. and Ventura, A. (2020), "Analysis of the SEO visibility of university libraries and how they impact the web visibility of their universities", The Journal of Academic Librarianship, Vol. 46 No. 4, p. 102171.

Vállez, M., Lopezosa, C. and Pedraza-Jiménez, R. (2021), Data: Web Visibility of the SDGs and the 2030 Agenda on University Websites, Figshare Dataset, doi: 10.6084/m9.figshare.16817950.v1, available at: https://figshare.com/articles/dataset/Data_Web_visibility_of_the_SDGs_and_the_2030_Agenda_on_ university_websites/16817950/1

Vyas, C. (2019), "Evaluating state tourism websites using search engine optimization tools", Tourism Management, Vol. 73, pp. 64-70.

Windia, E., Yulianingsih, A., Prasetya, R., Cholifah, W. and Rahim, R. (2018), "Applying C-FDT as making decision for the content of SEO media online", Journal of Physics: Conference Series, Vol. 1363, pp. 1-7.

Yalcin, N. and Kilic, A. (2016), "A comparison of private university websites in Ankara according to their search engine optimizations", AJIT-e: Online Academic Journal of Information Technology, Vol. 7 No. 23, pp. 55-66.

Yudasubrata, A.T.W., Damanik, R.O.P., Hidayanto, A.N. and Budi, N.F.A. (2019), "Search engine optimization (SEO) approach in studying information demand and supply: methodology of geotargeted keywords with case study of hospital websites in Jakarta”, 2019 International Conference on Advanced Computer Science and information Systems (ICACSIS), pp. 519-524.

Zheluk, A., Gillespie, J. and Casey, B.A. (2012), "Searching for truth: internet search patterns as a method of investigating online responses to a Russian illicit drug policy debate", Journal of Medical Internet Research, Vol. 14 No. 6, pp. 1-16.

Ziakis, C., Vlachopoulou, M., Kyrkoudis, T. and Karagkiozidou, M. (2019), "Important factors for improving Google search rank", Future Internet, Vol. 11 No. 2, pp. 1-12.

Ziewitz, M. (2019), "Rethinking gaming: the ethical work of optimization in web search engines", Social Studies of Science, Vol. 49 No. 5, pp. 707-731. 


\title{
Appendix
}

Control test: The results obtained with the two platforms, SEMrush and Sistrix, for the three terms related to SDGs are aligned, although they cannot match completely because each platform has its of the SDGs own database. The data were collected on 31 August 2021.

\begin{tabular}{|c|c|c|c|c|c|}
\hline \multirow[b]{2}{*}{ Terms } & \multicolumn{2}{|c|}{ UAM } & \multicolumn{2}{|c|}{ Oxford University } & \multirow{5}{*}{$\begin{array}{r}\text { Table A1. } \\
\text { Control test: UAM } \\
\text { (uam.es) versus } \\
\text { Oxford University } \\
\text { (ox.ac.uk) }\end{array}$} \\
\hline & SEMrush & Sistrix & SEMrush & Sistrix & \\
\hline 2030 Agenda & 61 & 62 & 0 & 0 & \\
\hline SDGs & 5 & 1 & 3 & 0 & \\
\hline SDG & 128 & 187 & 8 & 6 & \\
\hline
\end{tabular}

\begin{abstract}
About the authors
Mari Vallez is a Lecturer at the Faculty of Information and Audiovisual Media at the University of Barcelona. She coordinates the double bachelor's degree in Digital Information and Documentation Management - Audiovisual Communication. She holds a PhD in Social Communication. Mari Vallez is the corresponding author and can be contacted at: marivallez@ub.edu

Carlos Lopezosa is an Associate Professor at the Pompeu Fabra University of Barcelona. He teaches at the Faculty of Communication, in the bachelor's degrees of Journalism and Audiovisual Communication. He is the Coordinator and Lecturer of the online master's degree in search engines and SEO/SEM at the Barcelona School of Management (UPF). He has a PhD in Information Sciences and is a specialist in SEO.

Rafael Pedraza-Jiménez is a Serra Húnter Associate Professor in the Department of Communication at Pompeu Fabra University. He has a $\mathrm{PhD}$ from the University of Barcelona. He is a member of the DigiDoc Research Group. He teaches in journalism studies at UPF and collaborates in master's degrees at different universities.
\end{abstract}

For instructions on how to order reprints of this article, please visit our website: www.emeraldgrouppublishing.com/licensing/reprints.htm Or contact us for further details: permissions@emeraldinsight.com 